that closure of the defect will be difficult without the use of cardiac arrest, the temperature can be lowered to the correct level and closure be performed under optimal conditions.

In one case where the defect was closed by direct suture, one suture tore out and so damaged the septum that a patch had to be overlaid to cover the tear. Unfortunately, in suturing this patch into position tricuspid incompetence was produced. The development of heart-block some 18 hours later was attributed to gross right ventricular dilatation causing tension on the sutures.

Three of the four patients who developed heart-block had unusual anatomical features in relation to the V.S.D. Sayed et al. (1961) showed the usual anatomy of the V.S.D. in the tetralogy of Fallot. In our experience, any departure from this pattern greatly increases the risk of heart-block occurring during closure or if distension of either ventricle produces tension in the V.S.D. sutures post-operatively.

The prophylactic insertion of a cardiac pacemaker electrode is now carried out to facilitate the immediate treatment of heartblock of late onset.

Of the four cases with heart-block, the survivor responded normally to artificial pacemaking, while the other three, although they responded normally at first, rapidly developed an increasing resistance requiring voltage increase from 1.5 to 12 volts over 12 to 24 hours. They then became completely resistant to any stimulation, and death followed. No satisfactory explanation for this phenomenon can be offered.

In all three patients dying of heart-block, cerebral disturbance became manifest soon after the onset of the block and severe cerebral damage was found at necropsy.
It is encouraging that, contrary to expectation, no trouble was experienced with respiration in the post-operative phase and tracheostomy was not required. The children were nursed flat in an oxygen tent for 48 hours and were then gradually weaned from it.

In two cases the children were bottle-fed without difficulty, but in all cases great care is needed to preserve post-operative biochemical equilibrium.

\section{Summary}

Fourteen children under the age of 5 years were operated upon for total correction of the tetralogy of Fallot, using cardiopulmonary by-pass and deep hypothermia. There were three fatalities. Ten were acyanotic and well, while one was still cyanosed owing to reopening of the ventricular septal defect but was greatly improved. There were no respiratory or haemorrhagic complications.

We should like to thank Mr. H. M. Bradmore for his assistance at all these operations; Dr. M. Yorston, who provided anaesthesia ; the paediatricians of the Wessex Region who referred the patients; and the medical and nursing staff of the Cardiac and Thoracic Unit for their unstinted help, without which this work would not have been possible.

\section{REFERENCES}

Drew, C. E., Keen, G., and Benazon, D. B. (1959). Lancet, 1, 745. Lillehei, C. W., Cohen, M., Warden, H. E., Read, R. C., Aust, J. B., De Wall, R. A., and Varco, R. L. (1955). Ann. Surg., 142, 418. Melrose, D. G. (1959). Brit. F. Anaesth., 31, 393.

Raison, J. C. A. (1963). Thorax, 18, 98.

Sayed, H., Bentall, H., and Melrose, D. (1962). Lancet, 1, 549.

\title{
Diffuse Mesothelioma of the Pleura and Asbestos
}

\author{
P. C. ELMES,* M.D., M.R.C.P. ; W. T. E. MCCAUGHEY,† M.D. ; O. L. WADE,* M.D., F.R.C.P.
}

Brit. med. F., 1965, 1, 350-353

Diffuse mesothelioma of the pleura is an uncommon tumour which, after prolonged controversy, has now become generally accepted as an entity (Campbell, 1950; Godwin 1957; McCaughey, 1958 ; Wagner, Munday, and Harington, 1962). Evidence has recently been accumulating that inhalation of asbestos may be an important factor in the aetiology of this tumour, and groups of cases associated with exposure to asbestos have been reported from South Africa (Wagner, Sleggs, and Marchand, 1960), Germany (König, 1960), the United Kingdom (McCaughey, Wade, and Elmes, 1962 ; Hourihane, 1964 ; Owen, 1964), and the United States (Selikoff, Churg, and Hammond, 1964). Crocidolite, the blue asbestos mined in South Africa, appears to be particularly carcinogenic in this respect (Wagner et al., 1960). There is also evidence that similar tumours arising in the peritoneum are also related to asbestos exposure (Keal, 1960 ; Enticknap and Smither, 1964 ; Hourihane, 1964).

In a previous report (McCaughey et al., 1962) we described the finding of asbestos bodies in the lungs of 12 out of 15 patients who had died of diffuse pleural mesothelioma in Belfast. Details of the working life were available for only nine of these patients, but in four of them there was a clear history of exposure to asbestos. This paper describes three further

\footnotetext{
* Department of Therapeutics and Pharmacology, the Queen's University

t Department of Pathology, the Queen's University of Belfast.
}

investigations carried out in Belfast: (1) a study of the industrial occupation of 42 patients with mesothelioma of the pleura and of 42 control patients without mesothelioma; (2) an investigation of the prevalence of asbestos bodies in the lungs of patients with and without mesothelioma of the pleura or carcinoma of the lung; and (3) an investigation of the relation between the presence of asbestos bodies in the lungs at death and a history of exposure to asbestos.

\section{Industrial Occupation}

Patients with Mesothelioma of the Pleura.-Occupational histories were obtained from the patients themselves or, if the patients had died, from friends and neighbours. Including those previously reported, 45 cases of mesothelioma of the pleura had been diagnosed in Belfast by the time this study was completed. Only 42 were included in the analysis because three of the early patients had died more than 15 years previously and no details were available.

Control Patients.-Occupational histories were obtained from matched controls selected from the records of the department of pathology. If diagnosis of mesothelioma of the pleura in the propositus had been made by biopsy the paired control was selected as that patient of the same sex and within 1 year of age whose name appeared closest to the name of the 
propositus in the "biopsy report book" in which a daily record of reports on biopsy specimens is kept. If diagnosis of mesothelioma of the pleura in the propositus had been made at necropsy the paired control patient was selected from the "necropsy report book" in the same way. The occupational histories of the paired control patients were obtained in the same way as for the patients with mesothelioma of the pleura and for 41 of the control patients. Information could not be obtained for one of the control patients initially selected, as he had lived in an area of extensive slum clearance and no relatives or neighbours could be traced. The next nearest suitable patient in the record book was chosen in his place.

The Taking of Histories.-Occupational histories were obtained by one of us from a few of the patients with mesothelioma and from a few of the control patients in hospital. Otherwise the industrial histories were obtained by one of two social workers with a special knowledge of the industrial processes in which asbestos may be a hazard. Their inquiries were greatly helped by the stability and social cohesion of the population of Belfast. Even when death had occurred many years ago close relatives were often still living at the same address, or neighbours knew how they might be found, or remembered the patient well enough to give some information about his occupation. Although the knowledge that informants gave of the type of work undertaken by patients was often limited, this defect applied equally to patients who had died of mesothelioma and to control patients.

Assessment of Exposure to Asbestos.-The asbestos used in the insulating and building industry in Belfast has varied in composition and contained crocidolite as well as chrysotile and amosite ; because of this no attempt was made to identify the material to which each individual was exposed. Exposure was assessed from the industrial history and graded arbitrarily as follows: Heavy exposure: A definite history of working with asbestos full-time for at least one year. Light exposure: A history of working with asbestos full-time for less than one year or of working over a period of many years at a job such as boiler repairer, plumber, or fitter in the shipyards with intermittent exposure to asbestos. No exposure: No history of exposure to asbestos.

Results.-The age, occupational history, and assessment of exposure to asbestos of the 42 patients with mesothelioma of the pleura and of the matched controls are summarized in Table I. At the time of diagnosis the mesothelioma patients

TABLE I.-Exposure to Asbestos

\begin{tabular}{|c|c|c|c|c|}
\hline & \multicolumn{3}{|c|}{ Exposure } & \multirow{2}{*}{ Total } \\
\hline & Heavy & Light & None & \\
\hline 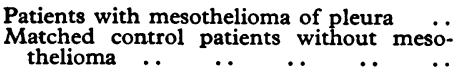 & $\begin{array}{l}8 \\
2\end{array}$ & $\begin{array}{r}24 \\
7\end{array}$ & $\begin{array}{l}10 \\
33\end{array}$ & $\begin{array}{l}42 \\
42\end{array}$ \\
\hline
\end{tabular}

Combining heavy- and light-exposure groups the difference between mesotheliomas and controls is highly significant $\left(x^{2}=25 \cdot 3\right.$. D of $F=1$. $\left.P<0 \cdot 001\right)$.
and

varied in age from 38 to 88 years (mean $59 \pm 10.9$ years standard deviation). There were only two women. In 32 of the 42 patients with mesothelioma there was a history of exposure to asbestos. In eight the exposure was assessed as heavy and in 24 as light. In the 42 paired control patients there was a history of exposure in nine, and in only two of these was it classified as heavy. This difference is .highly significant (differences are regarded as significant when $P<0.05$ ). Most of the individuals with heavy exposure had worked for some years as pipe-coverers or had of ten been exposed to asbestos dust in confined spaces when repairing boilers and steam pipes. Most of those classified under light exposure had worked in the shipyards as electricians, plumbers, or joiners, being intermittently exposed to asbestos dust when working close to pipecoverers in confined spaces. Shipyard workers were not classified as exposed to asbestos unless a definite exposure was described. In the cases where exposure to asbestos was admitted the duration of exposure varied from 3 to 56 years (mean $35.5+$ 15.3 years). The interval between first exposure and the diagnosis of mesothelioma varied from 22 to 73 years (mean $43.4 \pm 13$ years). Eighteen of the exposed cases were still working when they became disabled by their mesothelioma. In the remainder the interval between the last known exposure and the diagnosis of the disease varied from 2 to 49 years (mean $23.1 \pm 15.6$ years).

\section{Prevalence of Asbestos Bodies in Lungs}

Methods.-A search for asbestos bodies has been made by histological examination of all available sections (usually between two and six) of lung tissue from each patient studied. The result of the search was called positive if asbestos bodies were identified. To be identified asbestos bodies had to be of classical form-that is, yellowish brown or golden yellow in colour, elongated, and usually segmented. Shapes corresponding to those illustrated in Figures 8, 9, 10, 18, 21, 24, 25, 27, 32, 33, and 40 in the paper by Gloyne (1932) were most often seen.

Patients without Mesothelioma of the Pleura or Carcinoma of the Bronchus.-To determine the frequency with which asbestos fibres could be identified in the lungs of male patients dying in Belfast on whom necropsy was performed, lung sections were examined from 100 patients aged 50-59 and from 100 patients aged 60-69 years. The patients were chosen randomly from the " necropsy record books" except that those with mesothelioma of the pleura or carcinoma of the bronchus were excluded. Asbestos bodies were found in 14 of the 100 patients aged 50-59 years and in 27 of the 100 patients aged 60-69 years (Table II). The difference between these two groups is significant.

TABLE II.-Asbestos Bodies in Lungs

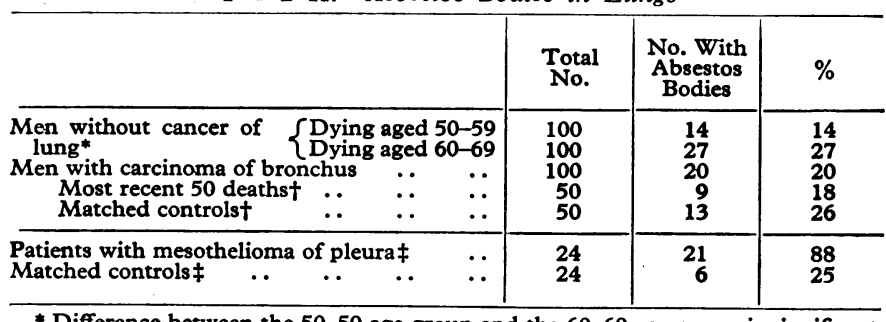

* Difference between the 50-59 age-group and the 60-69 age-group is significant $\left(\chi^{2}=5 \cdot 18\right.$. D of $\left.\mathrm{F}=1.0 .05>\mathrm{P}>0.02\right)$.

+ Difference between the 50 most recent deaths from carcinoma of bronchus and the 50 matched controls is not significant $\left(\chi^{2}=0.94\right.$. D of $\left.F=1.0 .4>P>0.3\right)$. $\ddagger$ Difference between the mesothelioma patients and controls is highly significant
$\left(x^{2}=19.04, D\right.$ of $\mathrm{F}=1$. $\left.\mathrm{P}<0.0005\right)$.

Patients with Carcinoma of the Bronchus.-Sections of lung tissue from 100 men who died with carcinoma of the bronchus were examined and asbestos bodies were identified in sections from 20 of them. For the 50 patients who had died most recently paired control patients without carcinoma of the lung were chosen. These controls were men of the same age whose names were closest to those of the propositi in the "necropsy record book." Among these 50 patients with carcinoma of the bronchus there were nine in whose lungs asbestos bodies were identified; in the 50 matched controls there were 13 in whose lungs asbestos bodies were identified. The difference is not significant (Table II).

Patients with Mesothelioma of the Pleura.-Necropsy material was available from only 24 of the patients who died with mesothelioma of the pleura. The lung tissue of matched control patients was also examined. The lungs of 21 of the 24 patients with mesothelioma of the pleura contained asbestos bodies. In four cases the sections showed numerous bodies, in the rest only small numbers were found. Asbestos bodies were identified in lung sections from only 6 of the 24 matched control patients who did not have mesothelioma of the pleura. This difference is highly significant (Table II). 


\section{Asbestos Bodies and Industrial History}

To throw light both on the meaning of the presence of asbestos bodies in lung tissues and on the accuracy of industrial histories taken after death from relatives, friends, or neighbours, 20 patients were chosen who had died in recent years, who had not had either carcinoma of the lung or mesothelioma of the pleura but in whose lung tissues at necropsy asbestos bodies had been identified. Matched control patients who had neither carcinoma nor mesothelioma and in whose lung tissues no asbestos bodies had been found were also selected, the controls being selected as that patient of the same age and sex whose name was nearest to that of the propositus in the "necropsy record book." The selection of the 40 patients was done by the pathologist (W. T. E. McC.).

The occupational history of each of these 40 patients was obtained by one of the social workers who visited and questioned relatives and friends. The exposure to asbestos was assessed from the industrial history as heavy, light, or none by the other two authors (P.C.E. and O.L.W.) before the pathologist revealed which were the patients in whom asbestos bodies had been identified and which were the controls.

Results.-The results are summarized in Table III. A history of heavy or light exposure to asbestos was elicited for 14 of the 20 patients whose lungs contained asbestos bodies,

TABLE III.-Asbestos Bodies in Lungs and Exposure

\begin{tabular}{l|c|c|c|c}
\hline & Total No. & \multicolumn{3}{|c}{ Exposure } \\
\cline { 2 - 4 } & & Heavy & Light & None \\
\hline $\begin{array}{l}\text { Asbestos bodies found in lung . . } \\
\text { Asbestos bodies not found in lung }\end{array}$ & 20 & 2 & 12 & 6 \\
\hline
\end{tabular}

Combining heavy- and light-exposure groups the difference between the group in whiom asbestos bodies were found and the control group was significant $\left(\chi^{2}=6 \cdot 42\right.$. $\mathrm{D}$ of $\mathrm{F}=1.0 .02>\mathrm{P}>0.01$ ).

but only two of these patients had had heavy exposure to asbestos. A history of exposure to asbestos was obtained from five of the 20 matched control patients in whose lungs no asbestos bodies were seen: only one of these had had heavy exposure. The differences in history of exposure to asbestos between the two groups are significant. In about a third of the patients who have had sufficient exposure to asbestos to have asbestos bodies identified in their lungs it has not been possible to obtain a history of exposure from relatives, friends, or neighbours. In a search for asbestos bodies in lung tissue, confined to the examination of two to six sections, asbestos bodies may not be found although the patient has been exposed to asbestos during his working life.

\section{Discussion}

Exposure to high concentrations of asbestos dust has long been known to cause asbestosis with fibrosis of the lung and pleura, and there is in this condition an increased incidence of carcinoma of the lung (Merewether, 1949; Doll, 1955). Although working conditions have been improved and the prevalence of asbestosis with severe fibrosis of the lung has been reduced, Williams and Hugh-Jones (1960) have shown that many workers in an asbestos factory may have disturbed lung function even though no pulmonary fibrosis has been detected by chest radiography.

The present investigation confirms that mesothelioma of the pleura is another hazard for those exposed to asbestos. Although mesothelioma is a rare tumour it has been possible to find in Belfast 45 patients with mesothelioma of the pleura confirmed histologically by biopsy or at necropsy. The true prevalence may well be higher, because the clinical diagnosis is difficult and without biopsy or necropsy the diagnosis must often be missed. In 1963, when physicians and surgeons in this area had become interested in this condition, 13 patients with mesothelioma of the pleura were found whereas previously never more than five patients had been discovered in a single year.

The investigation has shown that a history of exposure to asbestos during working life was found in about three-quarters of patients in whom a firm diagnosis of mesothelioma of the pleura was made compared with such a history in only onequarter of those without mesothelioma.

A study of the occupational histories suggests that the interval between first exposure to asbestos and the discovery of the tumour is often long and may exceed 40 years, and the exposure may be light and in some instances very transient. A similar observation was made by Wagner et al. (1960).

The long latent period means that the present incidence of this disease may have been determined by industrial practice 15 to 50 years ago ; it also means that preventive measures undertaken now will not affect the incidence for many years.

It is interesting that about a quarter of men dying recently between 60 and 69 years old in Belfast should have asbestos bodies in their lungs. These older men started their working life between 1905 and 1915. But asbestos bodies were found only in $14 \%$ of the younger men (dying between the ages of 50 and 59 years) who had started work between 1915 and 1925. The shipbuilding industry in Belfast was particularly active between 1906 and 1923 and over 1,000 tons of boiler insulation composition (containing asbestos) was used a year compared with a more usual level of 600 tons a year. By the time shipbuilding recovered from the slump and tried to meet the needs of the 1939-45 war, the dangers of handling asbestos were known and precautions were taken. The difference in frequency 'of finding asbestos fibres in the lungs of men in the two age-groups presumably reflects these changes in industrial conditions.

The shipyards are situated in a circumscribed area on the lough side. There is one small factory in which asbestos is used in the middle of a compact residential area. Plotting on a map the homes of patients with mesothelioma of the pleura does not show any geographical grouping to suggest contamination of a residential area by asbestos dust either from the factory or from the shipyards.

Until recently most asbestos used outside the shipyards was in the form of corrugated roofing. This was imported from England, and was usually cut and handled in the open under conditions of good ventilation. The use of asbestos in many industries, and especially in the building trade, is now increasing (The Times, 1964), and this gives rise to anxiety that there will be an increased incidence of mesothelioma of the pleura.

It is often difficult to obtain details of past employment from a patient, and this is especially difficult if the information sought concerns work done 30 or 40 years ago. From relatives or neighbours such information is bound to be less accurate, and this may account for the absence of a history of exposure to asbestos in some of the patients in whose lungs asbestos bodies were found, and possibly also in some of the patients with mesothelioma of the pleura. There are also instances in which asbestos bodies were not found in the lungs of men who had had heavy and prolonged exposure to asbestos. Both these errors would tend to lead in this investigation to an underestimation of the part played by exposure to asbestos in the aetiology of mesothelioma of the pleura.

\section{Summary}

A history of occupational exposure to asbestos was obtained in 32 out of 42 patients with mesothelioma of the pleura in Belfast. In 42 matched control patients of the same age and sex a history of exposure was obtained in only nine.

Asbestos bodies were found at necropsy in the lungs of 14$27 \%$ of men aged 50 to 69 dying recently of diseases other than 
carcinoma of the bronchus and mesothelioma of the pleura. Asbestos bodies were found in the lungs of about $20 \%$ of patients dying with carcinoma of the lung. They were found in more than $80 \%$ of men dying of mesothelioma of the pleura.

A history of an industrial occupation with exposure to asbestos was obtained from relatives, neighbours, or friends of about three-quarters of patients in whom asbestos bodies were found in the lungs at necropsy. Such a history was obtained for one-quarter of patients in whom asbestos bodies were not found in the lungs at necropsy.

It is concluded that there is evidence that exposure to asbestos, even though it may have been transient and many years previous, is an important factor in the aetiology of mesothelioma of the pleura. This conclusion gives cause for anxiety because of the increasing commercial use of asbestos.

We wish to thank Mrs. Yvonne Dudgeon and Mrs. Marion Simpson who worked untiringly with patience and tact to obtain occupational histories from patients or their relatives, friends, or neighbours. We are grateful to the records officers of Belfast hospitals for their help in searching out old notes and to many colleagues who have helped by referring patients to us. We wish to thank Dr. Merrett, of the Department of Social Medicine, for statistical advice. We are indebted for grants to the Stewart Friar Fund administered by the Faculty of Medicine of Queen's University, the British Empire Cancer Campaign, the Northern Ireland Hospitals Authority, the Royal Victoria Hospital Endowment Fund, and the Medical Research Council.

\section{REFERENCES}

Campbell, W. N. (1950). Amer. F. Path., 26, 473.

Doll, R. (1955). Brit. F. industr. Med., 12, 81.

Enticknap, J. B., and Smither, W. J. (1964). Ibid., 21, 20.

Gloyne, S. R. (1932). Lancet, 1, 1351.

Godwin, M. C. (1957). Cancer, 10, 298.

Hourihane, D. O'B. (1964). Thorax, 19, 268.

Keal, E. E. (1960). Lancet, 2, 1211.

Keal, E. E. (1960). Lancet, 2, 1211.

König, J. (1960). Arch. Gewerbepath. Gewerbehyg., 18, 159.

McCaughey, W. T. E. (1958). F. Path. Bact., 76, 517.

Wade, O. L., and Elmes, P. C. (1962). Brit. med. 7., 2, 1397.

Merewether, E. R. A. (1949). Annual Report of the Chief Inspector of Factories for the year 1947. H.M.S.O., London.

Owen, W. G. (1964). Brit. med. F., 2, 214.

Selikoff, I. J., Churg, J., and Hammond, E. C. (1964). f. Amer. med. Ass., 188, 22.

The Times (London), 5 March 1964, p. 17, col. 7.

The Times (London), 5 March 1964, p. 17, col. 7. S. (1962). 7. Path.

Bact., 84, 73.
Sleggs, C. A., and Marchand, P. (1960). Brit. F. industr. Med., 17, 260.

Williams, R., and Hugh-Jones, P. (1960). Thorax, 15, 109.

\title{
Serum Adenosine Deaminase in the Differential Diagnosis of Jaundice
}

\author{
D. M. GOLDBERG,* M.B., CH.B., B.SC.
}

Brit. med.F., 1965, 1, 353-355

The ability of most tissues of higher animals to convert adenosine to inosine and ammonia is due to a specific enzyme, adenosine deaminase. This enzyme was detected in whole blood and serum by Conway and Cooke (1939).

After the demonstration of elevated serum adenosine deaminase activity in tumour-bearing animals (Straub et al., 1957) and in human patients with bronchial carcinoma (Letnansky and Seelich, 1958) a study was made of serum adenosine deaminase activity in human patients suffering from a variety of malignant and non-malignant diseases (Koehler and Benz, 1962). The last of these authors reported a significant but non-diagnostic elevation of serum adenosine deaminase activity in the malignant group. On the other hand, the highest activities in the series were found among patients with infectious mononucleosis and hepatitis.

The present report concerns an investigation of serum adenosine deaminase activity in a large group of patients with and without jaundice, and it has been found that the estimation is of value in distinguishing between jaundice due to obstructive and hepatocellular causes.

\section{Materials and Methods}

Four categories of patient were studied.

Group A.-This group consisted of 52 healthy blood donors and patients prior to elective operations for herniae and varicose veins. Sex incidence was males 34 and females 18, and ages ranged from 2 to 79 years.

* Senior Registrar, Department of Biock mistry, Western. Infirmary, Glasgow, and the Department of Pathological Biochemistry, University of Glasgow.
Group B.-This group consisted of 50 patients suffering a variety of primary diseases, in the course of which the clinician suspected hepatic complications, but in whom neither jaundice nor any other clinical or laboratory parameter of such complications was detected after careful investigation. The cases were distributed as follows: cancer 22; myocardial infarction 4; congestive cardiac failure 4; reticuloses 4 ; muscular dystrophy 3 ; miscellaneous gastro-intestinal disorders 10 ; chronic alcoholism 3.

Group C.-This group consisted of 58 jaundiced patients in whom the cause was clearly obstructive. Cases with radiological evidence of stones in the biliary tract, or of hepatomegaly in known cancer cases, were included if the biochemical data were diagnostic. In all other cases within this group (48) the diagnosis was established at laparotomy or necropsy. In 30 cases the obstruction was associated with malignancy. The remainder were cases of cholelithiasis with or without associated cholecystitis.

Group D.-This group consisted of 55 jaundiced patients in whom the cause was clearly hepatocellular. This was established by histological examination in 28 . The remainder were cases of infectious hepatitis and cirrhosis showing the classical clinical and laboratory features of these conditions, together with four cases of acute jaundice following administration of known hepatotoxic drugs (chlorpromazine, two cases; para-aminosalicylic acid, two cases) subsiding on withdrawal of the suspected agent. In this group there were 26 cases of portal cirrhosis, 15 cases of infectious hepatitis, 4 cases of biliary cirrhosis, and 6 cases of miscellaneous subacute or chronic hepatocellular affections.

Serum adenosine deaminase activity was measured by a spectrophotometric method based on that of Solomon (1960). The optical density of a solution containing $20 \mu \mathrm{g}$. of adenosine per ml. of $0.1 \mathrm{M}$ phosphate buffer $p \mathrm{H} 7$ was read at $265 \mathrm{~m} \mu$ in a $1-\mathrm{cm}$. light path immediately after addition of serum (0.05 ml. $/ 3 \mathrm{ml}$. buffer-substrate mixture) and again after incubation at $37^{\circ} \mathrm{C}$. for one hour, the spectrophotometer being set at zero, using $0.05 \mathrm{ml}$. of serum in $3 \mathrm{ml}$. of $0.1 \mathrm{M}$ 